\title{
Transcription Syndromes and the Role of RNA Polymerase II General Transcription Factors in Human Disease
}

\author{
Teijiro Aso, Ali Shilatifard, Joan Weliky Conaway, and Ronald C. Conaway \\ Program in Molecular and Cell Biology, Oklahoma Medical Research Foundation, Oklahoma City, Oklahoma 73104
}

Messenger RNA synthesis is a major site for the regulation of gene expression. Eukaryotic messenger RNA synthesis is catalyzed by multisubunit RNA polymerase II (1-3) and proceeds via multiple stages, which are designated preinitiation, initiation, elongation, and termination and which have come to be referred to collectively as the transcription cycle (Fig. 1). The past decade was a watershed for biochemical studies of eukaryotic messenger RNA synthesis. A diverse collection of transcription factors and other nuclear proteins that govern the activity of RNA polymerase II during messenger RNA synthesis was identified and characterized, and unprecedented progress in several key research areas has provided a deeper understanding of the biochemical mechanisms underlying many aspects of eukaryotic transcriptional regulation.

First, major breakthroughs in investigations of the structures of eukaryotic protein-coding genes and the role of chromatin in the regulation of their expression were achieved. Chromatin proteins, such as histones and HMG proteins, were found to play crucial roles in gene regulation by packaging genes into inactive or transcriptionally repressed configurations (4-9). Second, many DNA binding transactivators that interact specifically with upstream promoter elements and enhancer sequences located in the promoter-regulatory regions of genes were isolated, classified according to their structures, and found to regulate the expression of specific genes or gene families by controlling the rate of initiation (10) and, as shown more recently, the efficiency of elongation by RNA polymerase II (11-13). Third, chromatin remodeling proteins, such as the multisubunit SWI/SNF $(14,15)$ and NURF $(16,17)$ complexes, were discovered and found to play key roles in transcriptional activation by promoting conversion of regions of inactive chromatin into transcriptionally active, open chromatin, thereby allowing DNA binding transactivators and RNA polymerase II access to the promoter-regulatory regions of genes (4, 18-23). Fourth, coactivators, such as the SRB-containing mediator complex $(2,3,24,25)$, CREB binding protein $(\mathrm{CBP})^{1}$ (26-28), octamer binding protein Bob1 (29), and PC4 $(30,31)$, which appear to expedite transcriptional activation by promot-

Address correspondence to Ronald C. Conaway, Program in Molecular and Cell Biology, Oklahoma Medical Research Foundation, 825 N.E. 13th Street, Oklahoma City, OK 73104. Phone: 405-271-1950; FAX: 405-271-1580.

Received for publication 17 January 1996.

J. Clin. Invest.

(C) The American Society for Clinical Investigation, Inc.

0021-9738/96/04/1561/09 \$2.00

Volume 97, Number 7, April 1996, 1561-1569 ing essential communication between DNA binding transactivators and RNA polymerase II, were discovered. Finally, in no area of research on the mechanism of eukaryotic messenger RNA synthesis has the pace of progress been more striking than in investigations of the "general" transcription factors, which have been shown to play fundamental roles in all stages of transcription by RNA polymerase II (32-34). As a consequence of an intense biochemical campaign, a large number of general factors has been identified, purified to homogeneity, their genes cloned, and working models for their roles in initiation and elongation established.

Biochemically defined general transcription factors include the general initiation factors TFIIB, TFIID, TFIIE, TFIIF, and TFIIH, which are essential for selective binding of RNA polymerase II to promoters and for synthesis of the first few phosphodiester bonds of nascent transcripts (32), and the general elongation factors SII, TFIIF, P-TEFb, Elongin (SIII), and ELL, which promote efficient elongation of transcripts by RNA polymerase II $(33,34)$. The general transcription factors are characterized by their ability to control the activity of RNA polymerase II, by their apparent role in transcription of most, if not all, eukaryotic protein-coding genes, and by their striking structural and functional conservation in eukaryotes from Saccharomyces cerevisiae to humans.

In addition to providing substantial insight into the functions of the general transcription factors in eukaryotic messenger RNA synthesis, these basic biochemical studies have recently led to several discoveries that have brought to light unexpected roles for the general factors in other aspects of human biology and in human disease. It had been well established that mutations in gene-specific, DNA binding transactivators such as Fos, Jun, and NF-кB could predispose affected individuals to a variety of genetic diseases including cancer (35). The possibility that mutations in genes encoding the general transcription factors might play an important role in human disease had been largely overlooked, however, because it was anticipated that mutations in the general factors, which play integral roles in transcription of all or most genes, would have catastrophic consequences for cell viability. Within the past several years, new evidence implicating the general factors in human genetic disorders and in oncogenesis has reshaped our conception of the roles these transcription factors play in human biology.

1. Abbreviations used in this paper: $\mathrm{CBP}, \mathrm{CREB}$ binding protein; $\mathrm{CS}$, Cockayne syndrome; NER, nucleotide excision repair; TBP, TATAbinding protein; TTD, trichothiodystrophy; VHL, von HippelLindau; XP, Xeroderma pigmentosum. 


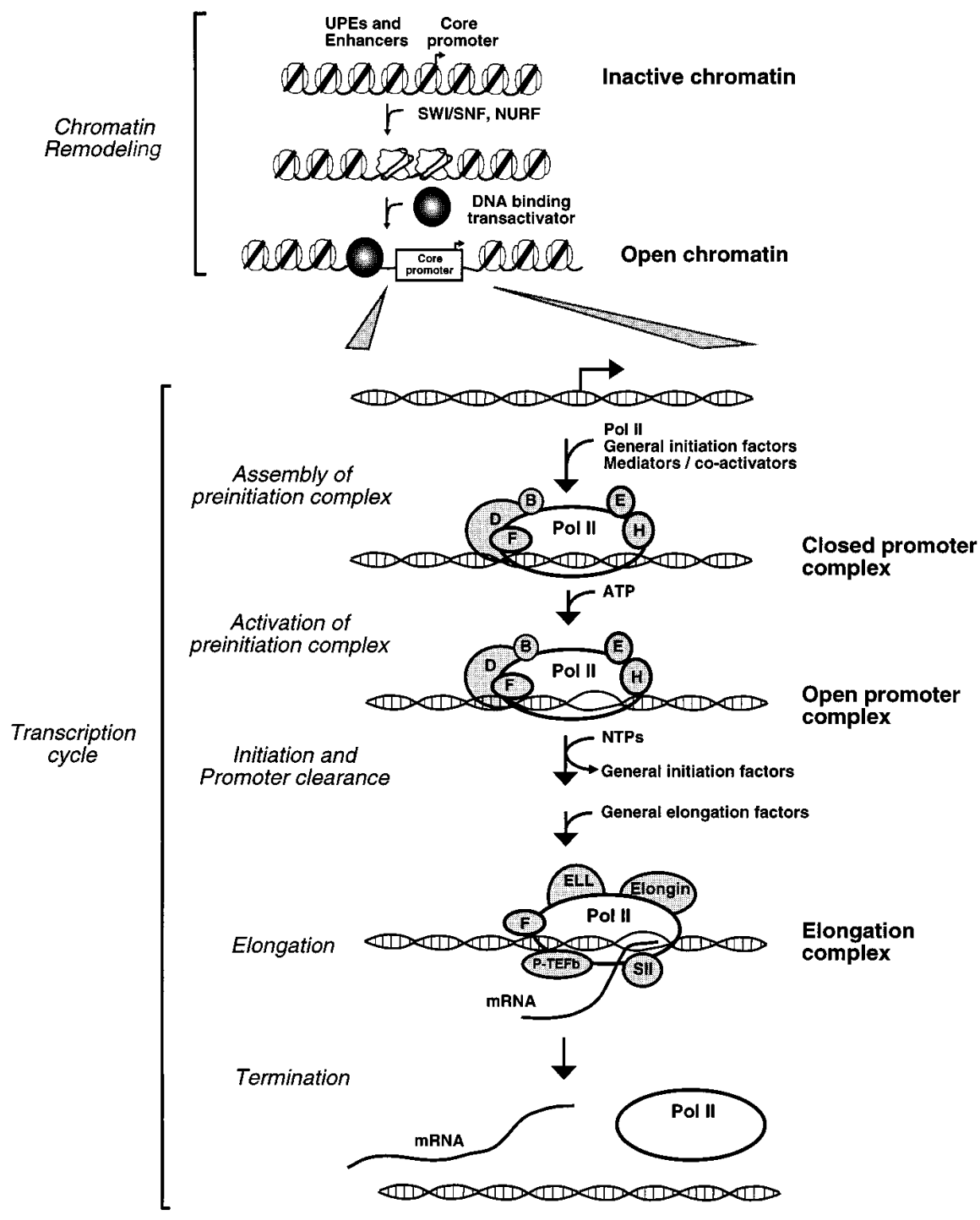

Figure 1. Steps in synthesis of a eukaryotic messenger RNA. In regions of inactive chromatin, the DNA template is assembled into a tightly packaged nucleosomal array; promoter elements, which include enhancers and binding sites for DNA binding transactivators, RNA polymerase II, and the general initiation factors, are occluded. Activation of transcription of many eukaryotic protein-coding genes is believed to be initiated by disruption of regions of inactive chromatin by chromatin remodeling proteins like the multisubunit SWI/SNF and

NURF complexes, which deform or "loosen" nucleosomes enough to allow access of DNA binding transactivators, RNA polymerase II, and the general initiation factors to the promoter-regulatory regions of these genes. DNA binding transactivators, acting in concert with mediators/coactivators, promote binding of RNA polymerase II and the general initiation factors to the core promoter to form the closed promoter complex. Before transcription initiation, the closed promoter complex is converted to a transcriptionally competent, open promoter complex in an ATP-dependent activation step that most likely involves unwinding of a short stretch of core promoter DNA near the transcriptional start site by a DNA helicase activity associated with TFIIH. Upon formation of the open promoter complex, RNA polymerase II initiates transcription, clears the promoter, and enters the elongation stage of messenger RNA synthesis. The general initiation factors are presumably released from the RNA polymerase II elongation complex at this stage. For simplicity, the figure shows simultaneous interaction of S-II, TFIIF, ELL, Elongin, and P-TEFb with the elongation complex; whether all of these

factors in fact act together is not known. Elongation continues until messenger RNA synthesis is complete. Finally, RNA polymerase II terminates transcription, releasing both its transcript and the DNA template. UPEs, upstream promoter elements; NURF, nucleosome remodeling factor; Pol II, RNA polymerase II; $B$, TFIIB; $D$, TFIID; $E$, TFIIE; $F$, TFIIF; $H$, TFIIH; NTPs, ribonucleoside triphosphates.

\section{The general initiation factors and their roles in promoter-specific transcription}

Initiation of messenger RNA synthesis by RNA polymerase II requires the concerted action of at least five general initiation factors (Table I), which assist polymerase to bind selectively to core promoters to form a functional preinitiation complex (32, 36). Core promoters recognized by RNA polymerase II often include a TATA element located 25-30 nucleotides upstream of the transcriptional start site. An additional promoter element, referred to as the initiator element and having the consensus sequence $(\mathrm{Py})_{45} \mathrm{CANT}(\mathrm{Py})_{4-5}$, is often found at the transcriptional start site (37). Assembly of the preinitiation complex is nucleated by sequence-specific binding of TFIID to the core promoter to form the nucleoprotein recognition site for RNA polymerase II on the DNA. TFIID, a high molecular mass complex composed of the TATA-binding protein (TBP) and 8-12 additional subunits referred to as TBP-associated factors or TAFs, is the only component of the RNA poly- merase II preinitiation complex with substantial sequence-specific DNA binding activity (38-40). Among the subunits of TFIID are at least two sequence-specific DNA binding proteins, TBP, which binds to the TATA element, and TAF150, which can bind the initiator element (41). The combined DNA binding activities of these two TFIID subunits most likely account for the majority of the sequence-specific DNA binding activity of TFIID.

Selective binding of RNA polymerase II to TFIID at the promoter requires TFIIB. TFIIB functions as a "bridging factor" that promotes binding of polymerase to the core promoter through direct interactions with both TFIID and RNA polymerase II (42) and is responsible for establishing the proper spacing between the TATA element and transcriptional start site $(43,44)$. The association of polymerase with its promoters is further stabilized by TFIIF (45-47), which binds stably to RNA polymerase II in solution and can enter the preinitiation complex either in association with or subsequent 
Table I. General Initiation Factors for RNA Polymerase II

\begin{tabular}{llll}
\hline Factor & \multicolumn{1}{c}{ Structure } & \multicolumn{1}{c}{ Polypeptides* } & \multicolumn{1}{c}{ Functions } \\
\hline TFIID & Multisubunit & TBP and $\geq 8$ TAFs & Core promoter binding \\
TFIIB & Monomer & $35 \mathrm{kD}$ & Bridge between Pol II and TFIID \\
TFIIF & Heterodimer & $30 \mathrm{kD}, 70 \mathrm{kD}$ & Stabilizes Pol II-TFIID binding \\
TFIIE & Heterodimer & $34 \mathrm{kD}, 58 \mathrm{kD}$ & Required for open complex formation \\
TFIIH & Multisubunit & 8 subunits & Has associated DNA helicase and \\
& & & CTD kinase activities; required \\
& & & for open complex formation
\end{tabular}

* Polypeptide sizes shown are apparent molecular masses determined by SDS-PAGE. CTD, COOH-terminal domain of the largest RNA polymerase II subunit; Pol II, RNA polymerase II; TAF, TBP-associated factor.

to the binding of polymerase (48). The role of TFIIF in transcription is most likely not limited to stabilizing binding of RNA polymerase II to the core promoter, since initiation depends strongly on TFIIF even under conditions where it makes only a relatively small contribution to polymerase binding (45).

Entry of the final two general initiation factors, TFIIE and TFIIH, into the preinitiation complex results in formation of stable protein-DNA contacts near the transcriptional start site $(46,49)$. Whether TFIIE and TFIIH bind directly to the transcriptional start site or whether they induce RNA polymerase II or the other general initiation factors to bind this region of the core promoter is unclear. However, substantial evidence argues that the major contribution of TFIIE and TFIIH to formation of the active initiation complex is to promote ATPdependent formation of an open promoter complex by unwinding a short stretch of promoter DNA near the transcriptional start site before initiation (50-55). An ATP-dependent DNA helicase activity associated with $\operatorname{TFIIH}(56,57)$ is believed to be responsible for unwinding the promoter.

\section{TFIIH and human genetic disease}

TFIIH is a complex, multisubunit protein that was initially identified and purified as an RNA polymerase II general initiation factor from rat liver (58) and subsequently from $S$. cerevisiae (59) and human cells (60) (Table II). In addition to possessing DNA helicase activity, TFIIH is tightly associated with a protein kinase capable of phosphorylating the heptapeptide repeats in the carboxy-terminal domain of the largest subunit of RNA polymerase II (61-63). The TFIIH kinase has been shown recently to be the cyclin $\mathrm{H}$-dependent protein kinase MO15/cdk7 (64-67). Although the role of the TFIIH kinase is presently unknown, substantial evidence indicates that it is not essential for transcription initiation (68-70).

The first evidence for involvement of an RNA polymerase II general transcription factor in human disease came from the work of Egly and co-workers (56), who discovered that the largest subunit of human TFIIH is the product of the Xeroderma pigmentosum complementation group $\mathrm{B}$ (XP-B) gene. The XP-B gene had been shown previously to encode a DNA helicase essential for nucleotide excision repair (NER) of DNA damaged by exposure to ultraviolet light or chemical agents (71). The XP-B gene is mutated in a subpopulation of patients suffering from the human genetic diseases XP, Cockayne syndrome (CS), and trichothiodystrophy (TTD) (72). In subsequent studies, the second largest subunit of TFIIH was shown to be the product of the XP-D gene (73-75). Like XP-B, XP-D encodes a DNA repair helicase that is mutated in a distinct subpopulation of patients with the same three genetic diseases. These findings raised the possibility that TFIIH might participate in both transcription and NER. A direct demonstration that TFIIH functions in NER came from the results of microinjection and in vitro NER assays (76-78).

$\mathrm{XP}, \mathrm{CS}$, and TTD are autosomal recessive diseases, all associated with deficiencies in NER (72). Originally considered distinct syndromes, they are now recognized as closely related diseases. The most outstanding clinical characteristics of XP are extreme sensitivity to sunlight-induced skin damage, hypo- and hyperpigmentation, and a marked pre-

Table II. TFIIH Subunits

\begin{tabular}{lll}
\hline Polypeptide* $^{*}$ Gene & \\
\hline $90 \mathrm{kD}$ & $X P-B$ & $3^{\prime} \rightarrow 5^{\prime}$ DNA helicase; DNA-dependent ATPase \\
$80 \mathrm{kD}$ & $X P-D$ & $5^{\prime} \rightarrow 3^{\prime}$ DNA helicase; DNA-dependent ATPase \\
$62 \mathrm{kD}$ & $p 62$ & \\
$44 \mathrm{kD}$ & $p 44$ & Zinc-finger protein \\
$41 \mathrm{kD}$ & $p 52$ & \\
$38 \mathrm{kD}$ & $M O 15 / C d k 7$ & CTD kinase; catalytic subunit of Cdk-activating kinase (Cak) \\
$34 \mathrm{kD}$ & $C y c l i n H$ & Cyclin subunit of Cak \\
$34 \mathrm{kD}$ & $p 34$ & Zinc-finger protein
\end{tabular}

*Polypeptide sizes shown are apparent molecular masses determined by SDS-PAGE. 
disposition to skin cancers. In addition, a subset of XP patients exhibits neurological or ocular abnormalities. By complementation analysis, XP has been divided into seven complementation groups (XP-A through XP-G), which all exhibit defective NER, and an eighth, variant XP group, which exhibits normal NER but defective postreplication repair. Individuals with the classical form of CS are sun sensitive but not cancer prone, short in stature, and suffer from severe mental retardation, microcephaly, and skeletal and retinal abnormalities. These patients fall into two complementation groups, CS-A and CS-B. The hallmarks of TTD are sulfur-deficient brittle hair, icthyosis, mental retardation, and abnormal facial features. Some TTD patients are sun sensitive but not cancer prone. A small subset of patients exhibiting features of XP and either CS, TTD, or both diseases has been identified. These patients fall into complementation groups XP-B, XP-D, and XP-G.

Identification of two TFIIH subunits as products of the XP-B and XP-D genes had two important consequences. First, these findings revealed the intimate relationship between the RNA polymerase II transcriptional machinery and the enzymes of NER. It had been recognized for some time that DNA damage in the template strand of actively transcribed genes is more efficiently repaired than damage in nontranscribed regions of the genome, leading to the proposal that the RNA polymerase II elongation complex is the target of a distinct transcription-coupled NER subpathway (79-81). The discovery that TFIIH is active in both transcription and NER provided the first solid biochemical evidence linking these two pathways.

Second, these findings provided the first direct evidence that mutations in genes encoding the cell's most basic transcriptional machinery could have clinical consequences, and they suggested a means of resolving a major question confronting investigators seeking to understand the molecular basis of XP, CS, and TTD. It was generally agreed that some XP, $\mathrm{CS}$, and TTD symptoms, including sensitivity to sunlight, pigmentation abnormalities, and, in the case of XP, the extreme risk of developing skin cancer, could be easily rationalized as DNA repair defects. On the other hand, many other features of these diseases, including mental retardation, neurodysmyelination, poor physical and sexual development, dental caries, ichthyosis, and brittle hair and nails, were difficult to rationalize as DNA repair defects. The finding that TFIIH plays roles in both NER and transcription led Bootsma and Hoeijmakers (82) to propose, first, that the unusual variety of clinical symptoms exhibited by patients with mutations in XP-B and XP-D might result, not from defective TFIIH function in NER, but rather from defective TFIIH function in transcription and, second, that there might be additional "transcription syndromes" resulting from other defects in the cell's basic transcriptional machinery.

Given biochemical and genetic evidence that TFIIH plays an important role in the transcription of all or most genes, how might mutations in this general transcription factor give rise to specific clinical phenotypes? One possibility is that TFIIH mutations could lead to a relatively small but uniform decrease in the efficiency with which all genes are transcribed. Alternatively, mutations in TFIIH could subtly alter transcription of select subsets of genes. Several recent studies suggest that the degree of dependence of transcription on TFIIH may vary depending on the degree of negative supercoiling of the core pro- moter (52-55). In addition, evidence suggests that TFIIH can counteract the repressive effect of HMG2 and perhaps other nonhistone chromosomal proteins (83). Thus, depending on the degree of supercoiling and local chromatin environment of their promoters, transcription of certain genes could be particularly sensitive to mutations in TFIIH. In either case, the resulting subtle alterations in transcription levels of genes that must be abundantly expressed or expressed at precisely controlled levels could give rise to the observed clinical phenotypes. As proposed by Vermeulen et al. (84), for example, the characteristic neurodysmyelination seen in XP, CS, and TTD patients could result from reduced transcription of the myelin basic protein gene, which must be expressed at high levels for proper nerve biogenesis and whose transcription is known to be rate-limiting for nerve growth in mice; likewise, the characteristic brittle hair seen in TTD and CS patients could result from reduced transcription of genes encoding the normally abundant cysteine-rich proteins of the hairshaft, and the characteristic ichthyoses seen in TTD and CS patients could result from reduced transcription of the filaggrin gene, which is normally expressed at high levels in skin.

\section{General elongation factors and human disease}

The existence of a class of general elongation factors that modulate RNA chain elongation by RNA polymerase II was predicted $>10 \mathrm{yr}$ ago by studies indicating that the mammalian enzyme lacks the capacity to catalyze RNA synthesis in vitro at rates $>100-300$ nucleotides/min (85), whereas messenger RNA synthesis in cells proceeds at rates of 1200-2000 nucleotides/min (86-88). The properties of these hypothetical general elongation factors were predicted by basic biochemical studies on the catalytic properties of mammalian RNA polymerase II. RNA chain elongation by RNA polymerase II is an inherently discontinuous process punctuated by frequent pausing and even premature termination at many sites within eukaryotic protein-coding genes $(33,34)$. As a consequence, general elongation factors that boost the overall elongation rate by suppressing transient pausing or preventing premature termination by elongating RNA polymerase II are predicted to play vital roles in timely expression of a large number of eukaryotic genes.

Indeed, eukaryotes have evolved such a family of general elongation factors. To date, biochemically defined members of this family include P-TEFb, SII, TFIIF, Elongin (SIII), and ELL (Table III). P-TEFb catalyzes the conversion of early, termination-prone transcription complexes into productive elongation complexes (89). The remaining general elongation factors fall into two functional classes. The sole member of the first class, SII (90), expedites elongation by preventing RNA polymerase II from terminating transcription prematurely at a variety of transcriptional impediments including DNA sequences that act as arrest sites, as well as some DNA-bound proteins and drugs. SII promotes readthrough of RNA polymerase II through these impediments by an unusual mechanism involving reiterative cycles of cleavage and reextension of nascent transcripts. The second class includes TFIIF (91-94), Elongin (SIII) $(95,96)$, and ELL (97), which all act to boost the overall rate of elongation by RNA polymerase II by suppressing transient pausing by polymerase at many sites within genes. Both Elongin (SIII) and ELL have been implicated recently in human disease. 
Table III. General Elongation Factors for RNA Polymerase II

\begin{tabular}{llll}
\hline \multicolumn{1}{c}{ Factor } & \multicolumn{1}{c}{ Structure } & Polypeptides* & \multicolumn{1}{c}{ Functions } \\
\hline SII & Monomer & $38 \mathrm{kD}$ & $\begin{array}{c}\text { Prevents premature termination or arrest } \\
\text { Converts termination-prone elongation complexes } \\
\text { P-TEFb }\end{array}$ \\
& Heterodimer & $124 \mathrm{kD}, 43 \mathrm{kD}$ & $\begin{array}{c}\text { Suppresses transient pausing } \\
\text { TFIIF }\end{array}$ \\
Elongin (SIII) & Heterodimer & $30 \mathrm{kD}, 70 \mathrm{kD}$ & Suppresses transient pausing \\
Elongin A & Elongin A, B, and C & & Transcriptionally active subuit \\
Elongin B & & $110 \mathrm{kD}$ & Regulatory subunit \\
Elongin C & $18 \mathrm{kD}$ & Regulatory subunit \\
ELL & $15 \mathrm{kD}$ & Suppresses transient pausing \\
\hline
\end{tabular}

* Polypeptide sizes shown are apparent molecular masses determined by SDS-PAGE.

Regulation of Elongin (SIII) by the product of the von Hippel-Lindau (VHL) tumor suppressor gene

The Elongin (SIII) complex can be purified from cells as a heterotrimer composed of $\mathrm{A}, \mathrm{B}$, and $\mathrm{C}$ subunits with apparent molecular masses of $\sim 110,18$, and $15 \mathrm{kD}(95,98-100)$. Biochemical studies have shown that Elongin A is transcriptionally active and that Elongin $\mathrm{B}$ and $\mathrm{C}$ regulate its activity by different mechanisms (98). Elongin $\mathrm{C}$ functions as a direct activator of Elongin A. Elongin $\mathrm{C}$ is capable of interacting directly with Elongin $\mathrm{A}$ in the absence of Elongin $\mathrm{B}$ to form an $\mathrm{AC}$ complex with increased specific activity. Elongin B, a member of the ubiquitin homology gene family, regulates the activity of Elongin C. Elongin B does not interact directly with Elongin A, but, instead, binds stably to Elongin C and facilitates assembly and stability of the Elongin (SIII) complex. In this respect, Elongin B appears to perform a chaperone-like role in assembly of the fully active Elongin (SIII) complex.

Evidence implicating the Elongin (SIII) complex in human genetic disease was obtained recently in experiments revealing that the Elongin $\mathrm{BC}$ complex is a target for negative regulation by the product of the VHL tumor suppressor gene (101). The VHL gene is mutated in families with VHL disease, a rare genetic disorder (incidence $\sim 1$ in 36,000) that predisposes individuals to a variety of cancers, including clear-cell renal carcinoma, hemangioblastomas, and pheochromocytomas (102-
105). Renal tumors from VHL patients carry the germline VHL mutation and show selective loss of the wild-type VHL allele inherited from the unaffected parent $(104,105)$. Of more general clinical importance, the majority of patients with sporadic clear-cell renal carcinoma show functional loss of both VHL alleles in their tumors (105-108). VHL mutations have also been identified in sporadic cerebellar hemangioblastomas (109), but are only very rarely observed in sporadic tumors from tissues not affected in VHL disease. The VHL tumor suppressor protein binds tightly and specifically to the Elongin BC complex both in vitro and in cells $(101,110)$. A subset of naturally occurring VHL mutants from VHL tumors and clear-cell renal carcinomas exhibits loss of binding to the Elongin $\mathrm{BC}$ complex, arguing that the VHL-Elongin BC interaction is likely to be important for the tumor suppressor function of VHL $(101,110)$. Binding of the VHL protein and Elongin A to the Elongin BC complex is mutually exclusive in vitro (101). Furthermore, binding of the VHL protein to the Elongin BC complex blocks its ability to activate Elongin A transcriptional activity (101). Taken together, these results suggest that the normal tumor suppressor function of the VHL protein may involve downregulation of Elongin (SIII) transcriptional activity (Fig. 2). Elongin (SIII) may therefore be a component of a transcriptional regulatory network controlled at least in part by the VHL protein.

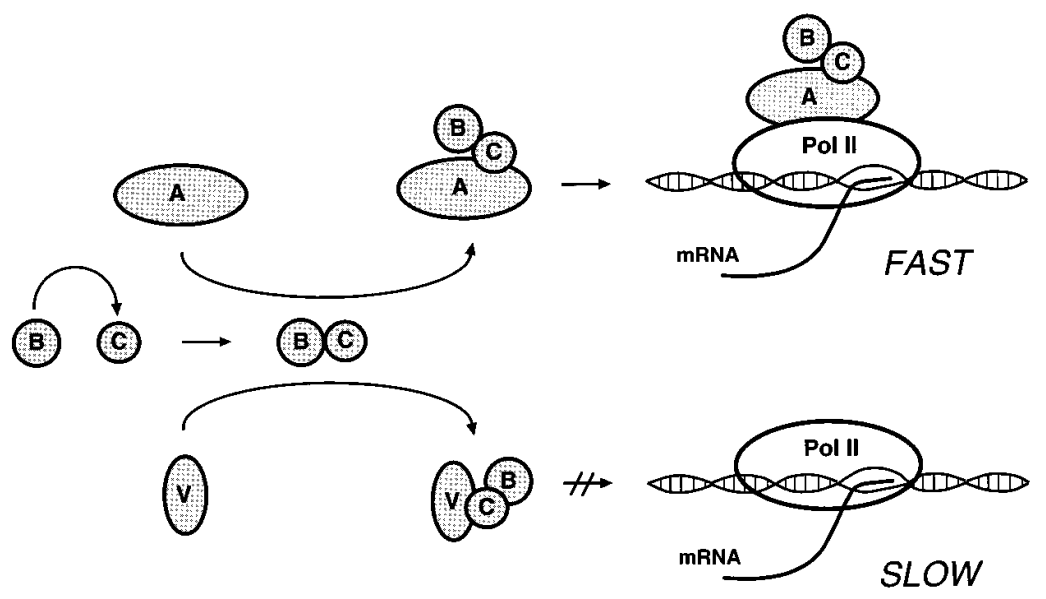

Figure 2. The Elongin (SIII) transcriptional regulatory pathway. Pol II, RNA polymerase II; $V$, von HippelLindau tumor suppressor protein; $A$, Elongin $\mathrm{A} ; B$, Elongin $\mathrm{B} ; C$, Elongin $\mathrm{C}$. 
ELL

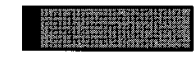

(19p13.1)

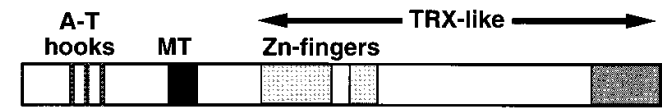

(11q23)

$M L$

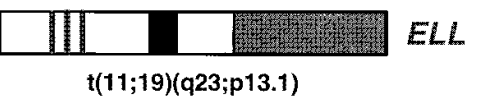

The human ELL gene in acute myeloid leukemia

The human ELL gene on chromosome 19p13.1 encodes an $\sim 80-\mathrm{kD}$ elongation factor (97) and is highly conserved and ubiquitously expressed in higher eukaryotes $(111,112)$. ELL was initially identified as a gene that undergoes frequent translocations with the Drosophila trithorax-like $M L L$ gene on chromosome 11q23 in acute myeloid leukemia (111, 112). $M L L$ encodes a 3,968-amino acid protein containing $\mathrm{NH}_{2}$-terminal A-T hook DNA binding and methyltransferase-like domains and a $\mathrm{COOH}$-terminal trithorax-like region composed of a transcriptional activation domain downstream of several contiguous zinc fingers $(113,114)$.

Characterization of chromosomal abnormalities in a large number of human cancers has revealed that the $M L L$ gene is a recurring target for translocations in a variety of clinically distinct leukemias (115). Genes encoding five $M L L$ translocation partners in addition to $E L L$ have been cloned. A remarkable
Elongation

factor

\section{DNA-binding}

transactivator?
Figure 3. Structure of the ELL fusion protein in acute myeloid leukemia. TRX, trithorax; $M T$, methyltransferase; $Z n$-fingers, zinc fingers.

feature of these translocations is that their breakpoints all result in creation of a putative oncogene encoding nearly the entire translocation partner fused to the $\mathrm{NH}_{2}$-terminal $\sim 1,400$ amino acids of the MLL protein, including its A-T hook and methyltransferase-like domains, but lacking its $\mathrm{COOH}$-terminal transcriptional activation domain and zinc fingers (Fig. 3). The finding that these translocation all occur within the same region of the $M L L$ gene, but are associated with clinically distinct leukemias, suggests that the $M L L$ translocation partner is likely to play a major role in establishing the leukemic phenotype.

To date, the ELL protein is the only MLL translocation partner with a known biochemical function. Interestingly, however, S. cerevisiae TFIIF copurifies with a protein, TFG3, which exhibits striking sequence similarity to another MLL translocation partner, ENL (116). Although no biochemical function for TFG3 has been discovered yet, it is tempting to

Table IV. Human Diseases Linked to Mutations in RNA Polymerase II Transcription Machinery

\begin{tabular}{|c|c|c|}
\hline Disease & Affected gene(s) & $\begin{array}{l}\text { Affected function; } \\
\text { transcription protein }\end{array}$ \\
\hline XP & $X P-B, X P-D$ & $\begin{array}{l}\text { Initiation; } \\
\text { TFIIH }\end{array}$ \\
\hline $\mathrm{CS}$ & $X P-B, X P-D$ & $\begin{array}{l}\text { Initiation; } \\
\text { TFIIH }\end{array}$ \\
\hline TTD & $X P-B, X P-D$ & $\begin{array}{l}\text { Initiation; } \\
\text { TFIIH }\end{array}$ \\
\hline VHL disease & VHL tumor suppressor & $\begin{array}{l}\text { Regulation of elongation; } \\
\text { Elongin }\end{array}$ \\
\hline $\begin{array}{l}\text { Sporadic clear-cell renal } \\
\text { carcinoma and } \\
\text { hemangioblastoma }\end{array}$ & VHL tumor suppressor & $\begin{array}{l}\text { Regulation of elongation; } \\
\text { Elongin }\end{array}$ \\
\hline Acute myeloid leukemia & $E L L$ & $\begin{array}{l}\text { Elongation; } \\
\text { ELL }\end{array}$ \\
\hline Rubenstein-Taybi syndrome & $C B P$ & $\begin{array}{l}\text { Coactivation; } \\
\text { CREB binding protein }\end{array}$ \\
\hline Benign mesenchymal tumors & $H M G I-C$ & $\begin{array}{l}\text { Chromatin structure; } \\
\text { HMGI-C }\end{array}$ \\
\hline $\begin{array}{l}\text { X-linked mental retardation } \\
\text { with } \alpha \text {-thalassemia }\end{array}$ & $X H 2$ & $\begin{array}{l}\text { Chromatin remodeling; } \\
\text { XH2 SW12/SNF2-like protein }\end{array}$ \\
\hline
\end{tabular}

$C R E B$, cAMP response element binding protein. 
speculate that, by virtue of its ability to interact with TFIIF, TFG3 could play a role in transcription.

\section{Future prospects}

Over the past decade, the marriage of biochemistry and human genetics has led to a revolution in our understanding of the molecular bases of human disease. Among many research areas that have flourished during this time, none has progressed more dramatically than studies on the role of transcriptional defects in human disease. Though the clinical consequences of defects in transcription factors belonging to the class of gene-specific transactivators are well established, the recent discovery of a variety of human genetic disorders linked to defects in the RNA polymerase II general transcription machinery (Table IV) was unexpected and has provoked new lines of investigation that will provide substantial insight into the roles these factors play in normal cell function and disease. A variety of recent evidence suggests that, in addition to defects in gene-specific transactivators and the general transcription factors, defects in other components of the cell's basic transcriptional machinery will also have clinical consequences. Within the past year, for example, mutations in genes encoding the CREB coactivator CBP $(26-28,117)$, the chromatin protein HMGI-C $(118,119)$, and the SWI2/SNF2-like protein encoded by the $\mathrm{XH} 2$ gene were found associated with Rubenstein-Taybi syndrome, lipomas and other benign mesenchymal tumors, and X-linked mental retardation with a-thalassemia, respectively. Future investigations of the roles these and other transcription proteins play in human disease will undoubtedly be an important component of our effort to elucidate their contribution to the regulation of eukaryotic gene expression.

\section{Acknowledgments}

Work in the authors' laboratory was supported by National Institutes of Health grant GM41628 and by funds provided to the Oklahoma Medical Research Foundation by the H.A. and Mary K. Chapman Charitable Trust. A. Shilatifard is supported by a postdoctoral fellowship from the Jane Coffin Childs Memorial Fund for Medical Research.

\section{References} 715

1. Young, R.A. 1991. RNA polymerase II. Annu. Rev. Biochem. 60:689-

2. Kim, Y.J., S. Bjorklund, Y. Li, M.H. Sayre, and R.D. Kornberg. 1994. A multiprotein mediator of transcriptional activation and its interaction with the C-terminal repeat domain of RNA polymerase II. Cell. 77:599-608.

3. Koleske, A.J., and R.A. Young. 1994. An RNA polymerase II holoenzyme responsive to activators. Nature (Lond.). 368:466-469.

4. Kornberg, R.D., and Y. Lorch. 1995. Interplay between chromatin structure and transcription. Curr. Opin. Cell Biol. 7:371-375.

5. Kornberg, R.D., and Y. Lorch. 1992. Chromatin structure and transcription. Annu. Rev. Cell Biol. 8:563-589.

6. Grunstein, M. 1990. Histone function in transcription. Annu. Rev. Cell Biol. 6:643-678.

7. Wolffe, A.P. 1994. Transcription: in tune with the histones. Cell. 77:1316.

8. Workman, J.L., and A.R. Buchman. 1993. Multiple functions of nucleosomes and regulatory factors in transcription. Trends Biochem. Sci. 18:90-95.

9. Paranjape, S.M., R.T. Kamakaka, and J.T. Kadonaga. 1994. Role of chromatin structure in the regulation of transcription by RNA polymerase II. Annu. Rev. Biochem. 63:265-297.

10. Tjian, R., and T. Maniatis. 1994. Transcriptional activation: a complex puzzle with few easy pieces. Cell. 77:5-8.

11. Bentley, D.L. 1995. Regulation of transcriptional elongation by RNA polymerase II. Curr. Opin. Genet. \& Dev. 5:210-216.

12. Yankulov, K., J. Blau, T. Purton, S. Roberts, and D.L. Bentley. 1994. Transcriptional elongation by RNA polymerase II is stimulated by transactiva- tors. Cell. 77:749-759.

13. Krumm, A., L.B. Hickey, and M. Groudine. 1995. Promoter-proximal pausing of RNA polymerase II defines a general rate-limiting step after transcription initiation. Genes \& Dev. 9:559-572.

14. Cairns, B.R., Y.J. Kim, M.H. Sayre, B.C. Laurent, and R.D. Kornberg. 1994. A multi-subunit complex containing the SWI1/ADR6, SWI2/SNF2, SWI3, SNF5, and SNF6 gene products isolated from yeast. Proc. Natl. Acad. Sci. USA. 91:1950-1954.

15. Peterson, C.L., A. Dingwall, and M.P. Scott. 1994. Five SWI/SNF gene products are components of a large multisubunit complex required for transcriptional enhancement. Proc. Natl. Acad. Sci. USA. 91:2905-2908.

16. Tsukiyama, T., and C. Wu. 1995. Purification and properties of an ATP dependent nucleosome remodelling factor. Cell. 83:1011-1020.

17. Tsukiyama, T., C. Daniel, J. Tamkun, and C. Wu. 1995. ISWI, a member of the SWI2/SNF2 ATPase family, encodes the $140 \mathrm{kDa}$ subunit of the nucleosome remodeling factor. Cell. 83:1021-1026.

18. Carlson, M., and B.C. Laurent. 1994. The SNF/SWI family of global transcriptional activators. Curr. Opin. Cell Biol. 6:396-402.

19. Wolffe, A.P. 1994. Switched-on chromatin. Curr. Biol. 4:525-528.

20. Tsukiyama, T., P.B. Becker, and C. Wu. 1994. ATP-dependent nucleosome disruption at a heat-shock promoter mediated by binding of GAGA transcription factor. Nature (Lond.). 367:525-532.

21. Cote, J., J. Quin, J.L. Workman, and C.L. Peterson. 1994. Stimulation of GAL4 derivative binding to nucleosomal DNA by the yeast SWI/SNF complex. Science (Wash. DC). 265:53-60.

22. Kwon, H., A.N. Imbalzano, P.A. Khavarl, R.E. Kingston, and M.R. Green. 1994. Nucleosome disruption and enhancement of activator binding by a human SWI/SNF complex. Nature (Lond.). 370:477-481.

23. Imbalzano, A.N., H. Kwon, M.R. Green, and R.E. Kingston. 1994. Facilitated binding of TATA-binding protein to nucleosomal DNA. Nature (Lond.). 370:481-485.

24. Hengartner, C.J., C.M. Thompson, J. Zhang, D.M. Chao, S.M. Liao, A.J. Koleske, S. Okamura, and R.A. Young. 1995. Association of an activator with an RNA polymerase II holoenzyme. Genes \& Dev. 9:897-910.

25. Liao, S.M., J. Zhang, D.A. Jeffery, A.J. Koleske, C.M. Thompson, D.M. Chao, M. Viljoen, H.J.J. van Vuuren, and R.A. Young. 1995. A kinase-cyclin pair in the RNA polymerase II holoenzyme. Nature (Lond.). 374:193-196.

26. Chrivia, J.C., R.P.S. Kwok, N. Lamb, M. Hagiwara, M.R. Montminy, and R.H. Goodman. 1993. Phosphorylated CREB binds specifically to the nuclear protein CBP. Nature (Lond.). 365:855-859.

27. Kwok, R.P.S., J.R. Lundblad, J.C. Chrivia, J.P. Richards, H.P. Bachinger, R.G. Brennan, S.G.E. Roberts, M.R. Green, and R.H. Goodman. 1994. Nuclear protein CBP is a coactivator for the transcription factor CREB. Nature (Lond.). 370:223-226.

28. Arias, J., A.S. Alberts, P. Brindle, F.X. Claret, T. Smeal, M. Karin, J. Feramisco, and M. Montminy. 1994. Activation of cAMP and mitogen responsive genes relies on a common nuclear factor. Nature (Lond.). 370:226-229.

29. Gstaiger, M., L. Knoepfel, O. Georgiev, W. Schaffner, and C.M. Hovens. 1995. A B-cell coactivator of octamer-binding transcription factors. Nature (Lond.). 373:360-362.

30. Kretzschmar, M., K. Kaiser, F. Lottspeich, and M. Meisterernst. 1994. A novel mediator of class II gene transcription with homology to viral immediateearly transcriptional regulators. Cell. 78:525-534.

31. Ge, H., and R.G. Roeder. 1994. Purification, cloning, and characterization of a human coactivator, PC4, that mediates transcriptional activation of class II genes. Cell. 78:513-523.

32. Conaway, R.C., and J.W. Conaway. 1993. General initiation factors for RNA polymerase II. Annu. Rev. Biochem. 62:161-190.

33. Aso, T., J.W. Conaway, and R.C. Conaway. 1995. The RNA polymerase II elongation complex. FASEB (Fed. Am. Soc. Exp. Biol.) J. 9:1419-1428.

34. Kerppola, T.K., and C.M. Kane. 1991. RNA polymerase: regulation of transcript elongation and termination. FASEB (Fed. Am. Soc. Exp. Biol.) J. 5 2833-2841.

35. Scriver, C.R., A.L. Beaudet, W.S. Sly, and D. Valle. 1995. The Metabolic and Molecular Bases of Inherited Disease. McGraw-Hill, Inc., New York. $4605 \mathrm{pp}$.

36. Buratowski, S. 1994. The basics of basal transcription by RNA polymerase II. Cell. 77:1-3.

37. Smale, S.T. 1994. Core promoter architecture for eukaryotic proteincoding genes. In Transcription: Mechanisms and Regulation. R.C. Conaway and J.W. Conaway, editors. Raven Press, New York. 63-81.

38. Zhou, Q., P.M. Lieberman, T.G. Boyer, and A.J. Berk. 1992. HoloTFIID supports transcriptional stimulation by diverse activators and from a TATA-less promoter. Genes \& Dev. 6:1964-1974.

39. Pugh, B.F., and R. Tjian. 1992. Diverse transcriptional functions of the multisubunit TFIID complex. J. Biol. Chem. 267:679-682.

40. Martinez, E., C.M. Chiang, H. Ge, and R.G. Roeder. 1994. TATA-binding protein-associated factor(s) in TFIID function through the initiator to direct basal transcription from a TATA-less class II promoter. EMBO (Eur. Mol. Biol. Organ.) J. 13:3115-3126.

41. Verrijzer, C.P., K. Yokomori, J.L. Chen, and R. Tjian. 1994. Drosophila TAFII150: similarity to yeast gene TSM-1 and specific binding to core promoter DNA. Science (Wash. DC). 264:933-941. 
42. Buratowski, S., S. Hahn, L. Guarente, and P.A. Sharp. 1989. Five intermediate complexes in transcription initiation by RNA polymerase II. Cell. 56: $549-561$

43. Pinto, I., D.E. Ware, and M. Hampsey. 1992. The yeast SUA7 gene encodes a homolog of human transcription factor TFIIB and is required for normal start site selection in vivo. Cell. 68:977-988.

44. Li, Y., P.M. Flanagan, H. Tschochner, and R.D. Kornberg. 1994. RNA polymerase II initiation factor interactions and transcription start site selection. Science (Wash. DC). 263:805-807.

45. Aso, T., J.W. Conaway, and R.C. Conaway. 1994. Role of core promoter structure in assembly of the RNA polymerase II preinitiation complex. A common pathway for formation of preinitiation intermediates at many TATA and TATA-less promoters. J. Biol. Chem. 269:26575-26583.

46. Conaway, R.C., K.P. Garrett, J.P. Hanley, and J.W. Conaway. 1991. Mechanism of promoter selection by RNA polymerase II: mammalian transcription factors alpha and beta gamma promote entry of polymerase into the preinitiation complex. Proc. Natl. Acad. Sci. USA. 88:6205-6209.

47. Flores, O., H. Lu, M. Killeen, J. Greenblatt, Z.F. Burton, and D. Reinberg. 1991. The small subunit of transcription factor IIF recruits RNA polymerase II into the preinitiation complex. Proc. Natl. Acad. Sci. USA. 88:999910003.

48. Greenblatt, J. 1991. RNA polymerase-associated transcription factors. Trends Biochem. Sci. 16:408-411.

49. Conaway, J.W., J.N. Bradsher, and R.C. Conaway. 1992. Mechanism of assembly of the RNA polymerase II preinitiation complex. Transcription factors delta and epsilon promote stable binding of the transcription apparatus to the initiator element. J. Biol. Chem. 267:10142-10148.

50. Wang, W., M. Carey, and J.D. Gralla. 1992. Polymerase II promoter activation: closed complex formation and ATP-driven start site opening. Science (Wash. DC). 255:450-453.

51. Holstege, F.C.P., P.C. van der Vliet, and H.Th.M. Timmers. 1996. Opening of an RNA polymerase II promoter occurs in two distinct steps and requires the basal transcription factors IIE and IIH. EMBO (Eur. Mol. Biol. Organ.) J. In press.

52. Timmers, H.Th.M. 1994. Transcription initiation by RNA polymerase II does not require hydrolysis of the beta-gamma phosphoanhydride bond of ATP. EMBO (Eur. Mol. Biol. Organ.) J. 13:391-399.

53. Holstege, F., D. Tantin, M. Carey, P.C. van der Vliet, and H.Th.M. Timmers. 1995. The requirement for basal transcription factor IIE is determined by the helical stability of promoter DNA. EMBO (Eur. Mol. Biol. Organ.) J. 14: 810-819.

54. Parvin, J.D., and P.A. Sharp. 1993. DNA topology and a minimal set of basal factors for transcription by RNA polymerase II. Cell. 73:533-540.

55. Parvin, J.D., B.M. Shykind, R.E. Meyers, J. Kim, and P.A. Sharp. 1994. Multiple sets of basal factors initiate transcription by RNA polymerase II. $J$. Biol. Chem. 269:18414-18421.

56. Schaeffer, L., R. Roy, S. Humbert, V. Moncollin, W. Vermeulen, J.H.J. Hoeijmakers, P. Chambon, and J.M. Egly. 1993. DNA repair helicase: a component of BTF2/TFIIH basic transcription factor. Science (Wash. DC). 260:58-63.

57. Serizawa, H., R.C. Conaway, and J.W. Conaway. 1993. Multifunctional RNA polymerase II initiation factor delta from rat liver: relationship between carboxyl-terminal domain kinase, ATPase, and DNA helicase activities. J. Biol. Chem. 268:17300-17308.

58. Conaway, R.C., and J.W. Conaway. 1989. An RNA polymerase II transcription factor has an associated DNA-dependent ATPase (dATPase) activity strongly stimulated by the TATA region of promoters. Proc. Natl. Acad. Sci. USA. 86:7356-7360

59. Feaver, W.J., O. Gileadi, and R.D. Kornberg. 1991. Purification and characterization of yeast RNA polymerase II transcription factor b. J. Biol. Chem. 266:19000-19005.

60. Gerard, M., L. Fischer, V. Moncollin, J.M. Chipoulet, P. Chambon, and J.M. Egly. 1991. Purification and interaction properties of the human RNA polymerase B(II) general transcription factor BTF2. J. Biol. Chem. 266:2094020945.

61. Feaver, W.J., O. Gileadi, Y. Li, and R.D. Kornberg. 1991. CTD kinase associated with yeast RNA polymerase II initiation factor b. Cell. 67:1223-1230.

62. Serizawa, H., R.C. Conaway, and J.W. Conaway. 1992. A carboxyl-terminal-domain kinase associated with RNA polymerase II transcription factor delta from rat liver. Proc. Natl. Acad. Sci. USA. 89:7476-7480.

63. Lu, H., L. Zawel, L. Fischer, J.M. Egly, and D. Reinberg. 1992. Human general transcription factor IIH phosphorylates the CTD-tail of RNA polymerase II. Nature (Lond.). 358:641-645.

64. Feaver, W.J., J.Q. Svejstrup, N.L. Henry, and R.D. Kornberg. 1994. Relationship of CDK-activating kinase and RNA polymerase II CTD kinase TFIIH/TFIIK. Cell. 79:1103-1109.

65. Roy, R., J.P. Adamczewski, T. Seroz, W. Vermeulen, J.P. Tassan, L. Schaeffer, E.A. Nigg, J.H.J. Hoeijmakers, and J.M. Egly. 1994. The MO15 cell cycle kinase is associated with the TFIIH transcription-DNA repair factor. Cell. 79:1093-1101.

66. Serizawa, H., T.P. Makela, J.W. Conaway, R.C. Conaway, R.A. Weinberg, and R.A. Young. 1995. Association of Cdk-activating kinase subunits with transcription factor TFIIH. Nature (Lond.). 374:280-282.
67. Shiekhattar, R., F. Mermelstein, R.P. Fisher, R. Drapkin, B. Dynlacht, H.C. Wessling, D.O. Morgan, and D. Reinberg. 1995. Cdk-activating kinase complex is a component of human transcription factor TFIIH. Nature (Lond.) 374:283-287.

68. Serizawa, H., J.W. Conaway, and R.C. Conaway. 1993. Phosphorylation of C-terminal domain of RNA polymerase II is not required in basal transcription. Nature (Lond.). 363:371-374.

69. Li, Y., and R.D. Kornberg. 1994. Interplay of positive and negative effectors in function of the C-terminal repeat domain of RNA polymerase II. Proc. Natl. Acad. Sci. USA. 91:2362-2366.

70. Makela, T.P., J.D. Parvin, J. Kim, L.J. Huber, P.A. Sharp, and R.A. Weinberg. 1995. A kinase-deficient transcription factor TFIIH is functional in basal and activated transcription. Proc. Natl. Acad. Sci. USA. 92:5174-5178.

71. Weeda, G., R.C. van Ham, W. Vermeulen, D. Bootsma, A.J. van der Eb, and J.H.J. Hoeijmakers. 1990. A presumed DNA helicase encoded by ERCC-3 is involved in the human repair disorders xeroderma pigmentosum and Cockayne's syndrome. Cell. 62:777-791.

72. Cleaver, J.E., and K.H. Kraemer. 1995. Xeroderma pigmentosum and Cockayne syndrome. In The Metabolic and Molecular Bases of Inherited Disease. C.R. Scriver, A.L. Beaudet, W.S. Sly, and D. Valle, editors. McGraw-Hill, Inc., New York. 4393-4419.

73. Feaver, W.J., J.Q. Svejstrup, L. Bardwell, A.J. Bardwell, S. Buratowski, K.D. Gulyas, T.F. Donahue, E.C. Friedberg, and R.D. Kornberg. 1993. Dual roles of a multiprotein complex from $\mathrm{S}$. cerevisiae in transcription and DNA repair. Cell. 75:1379-1387.

74. Schaeffer, L., V. Moncollin, R. Roy, A. Staub, M. Mezzina, A. Sarasin, G. Weeda, J.H. Hoeijmakers, and J.M. Egly. 1994. The ERCC2/DNA repair protein is associated with the class II BTF2/TFIIH transcription factor. EMBO (Eur. Mol. Biol. Organ.) J. 13:2388-2392.

75. Drapkin, R., J.T. Reardon, A. Ansari, J.C. Huang, L. Zawel, K. Ahn, A. Sancar, and D. Reinberg. 1994. Dual role of TFIIH in DNA excision repair and in transcription by RNA polymerase II. Nature (Lond.). 368:769-772.

76. Wang, Z., J.Q. Svejstrup, W.J. Feaver, X. Wu, R.D. Kornberg, and E.C Friedberg. 1994. Transcription factor b (TFIIH) is required during nucleotide excision repair in yeast. Nature (Lond.). 368:74-76.

77. van Vuuren, A.J., W. Vermeulen, L. Ma, G. Weeda, E. Appeldorn, N.G.J. Jaspers, A.J. van der Eb, D. Bootsma, J.H.J Hoeijmakers, S. Humbert, et al. 1994. Correction of xeroderma pigmentosum repair defect by basal transcription factor BTF2 (TFIIH). EMBO (Eur. Mol. Biol. Organ.) J. 13:16451653.

78. Aboussekhra, A., M. Biggerstaff, M. K.K. Shivji, J.A. Vilpo, V. Moncollin, V.N. Podust, M. Protic, U. Hubscher, J.M. Egly, and R. D. Wood. 1995. Mammalian DNA nucleotide excision repair reconstituted with purified protein components. Cell. 80:859-868.

79. Mellon, I., G. Spivak, and P.C. Hanawalt. 1987. Selective removal of transcription-blocking DNA damage from the transcribed strand of the mammalian DHFR gene. Cell. 51:241-249.

80. Hanawalt, P., and I. Mellon. 1993. Stranded in an active gene. Curr. Biol. 3:67-69.

81. Hanawalt, P.C. 1994. Transcription-coupled repair and human disease. Science (Wash. DC). 266:1957-1958.

82. Bootsma, D., and J.H.J. Hoeijmakers. 1993. Engagement with transcription. Nature (Lond.). 363:114-115.

83. Stelzer, G., A. Goppelt, F. Lottspeich, and M. Meisterernst. 1994. Repression of basal transcription by HMG2 is counteracted by TFIIH-associated factors in an ATP-dependent process. Mol. Cell. Biol. 14:4712-4721.

84. Vermeulen, W., A.J. van Vuuren, M. Chipoulet, L. Schaeffer, E. Appeldoorn, G. Weeda, N.G.J. Jaspers, A. Priestley, C.F. Arlett, A.R. Lehmann, et al. 1994. Three unusual repair deficiencies associated with transcription factor BTF2(TFIIH): evidence for the existence of a transcription syndrome. Cold Spring Harbor Symp. Quant. Biol. 59:317-329.

85. Izban, M.G., and D.S. Luse. 1992. Factor-stimulated RNA polymerase II transcribes at physiological elongation rates on naked DNA but very poorly on chromatin templates. J. Biol. Chem. 267:13647-13655.

86. Tennyson, C.N., H.J. Klamut, and R.G. Worton. 1995. The human dystrophin gene requires 16 hours to be transcribed and is cotranscriptionally spliced. Nat. Genet. 9:184-190.

87. Ucker, D.S., and K.R. Yamamoto. 1984. Early events in the stimulation of mammary tumor virus RNA synthesis by glucocorticoids. Novel assays of transcription rates. J. Biol. Chem. 259:7416-7420.

88. Thummel, C.S., K.C. Burtis, and D.S. Hogness. 1990. Spatial and temporal patterns of E74 transcription during Drosophila development. Cell. 61:101111.

89. Marshall, N.F., and D.H. Price. 1995. Purification of P-TEFb, a transcription factor required for the transition into productive elongation. J. Biol. Chem. 270:12335-12338.

90. Reines, D. 1994. Nascent RNA cleavage by transcription elongation complexes. In Transcription: Mechanisms and Regulation. R.C. Conaway and J.W. Conaway, editors. Raven Press, New York. 263-278.

91. Price, D.H., A.E. Sluder, and A.L. Greenleaf. 1989. Dynamic interaction between a Drosophila transcription factor and RNA polymerase II. Mol. Cell. Biol. 9:1465-1475. 
92. Kephart, D.D., B.Q. Wang, Z.F. Burton, and D.H. Price. 1994. Functional analysis of Drosophila factor 5 (TFIIF), a general transcription factor. $J$. Biol. Chem. 269:13536-13543.

93. Tan, S., T. Aso, R.C. Conaway, and J.W. Conaway. 1994. Roles for both the RAP30 and RAP74 subunits of transcription factor IIF in transcription initiation and elongation by RNA polymerase II. J. Biol. Chem. 269:25684-25691.

94. Tan, S., R.C. Conaway, and J.W. Conaway. 1995. Dissection of transcription factor TFIIF functional domains required for initiation and elongation. Proc. Natl. Acad. Sci. USA. 92:6042-6046.

95. Bradsher, J.N., K.W. Jackson, R.C. Conaway, and J.W. Conaway. 1993. RNA polymerase II transcription factor SIII. I. Identification, purification, and properties. J. Biol. Chem. 268:25587-25593.

96. Bradsher, J.N., S. Tan, H.-J. McLaury, J.W. Conaway, and R.C. Conaway. 1993. RNA polymerase II transcription factor SIII. II. Functional properties and role in RNA chain elongation. J. Biol. Chem. 268:25594-25603.

97. Shilatifard, A., W.S. Lane, K.W. Jackson, R.C. Conaway, and J.W. Conaway. 1996. The human ELL gene encodes a novel RNA polymerase II elongation factor. Science (Wash. DC). In press.

98. Aso, T., W.S. Lane, J.W. Conaway, and R.C. Conaway. 1995. Elongin (SIII): a multisubunit regulator of elongation by RNA polymerase II. Science (Wash. DC). 269:1439-1443.

99. Garrett, K.P., S. Tan, J.N. Bradsher, W.S. Lane, J.W. Conaway, and R.C. Conaway. 1994. Molecular cloning of an essential subunit of RNA polymerase II elongation factor SIII. Proc. Natl. Acad. Sci. USA. 91:5237-5241.

100. Garrett, K.P., T. Aso, J.N. Bradsher, S.I. Foundling, W.S. Lane, R.C. Conaway, and J.W. Conaway. 1995. Positive regulation of general transcription SIII by a tailed ubiquitin homolog. Proc. Natl. Acad. Sci. USA. 92:7172-7176.

101. Duan, D.R., A. Pause, W.H. Burgess, T. Aso, D.Y.T. Chen, K.P. Garrett, R.C. Conaway, J.W. Conaway, W.M. Linehan, and R.D. Klausner. 1995. Inhibition of transcription elongation by the VHL tumor suppressor protein. Science (Wash. DC). 269:1402-1406.

102. Latif, F., K. Tory, J. Gnarra, M. Yao, F.M. Duh, M.L. Orcutt, T. Stackhouse, I. Kuzmin, W. Modi, L. Geil, et al. 1993. Identification of the von Hippel-Lindau Disease tumor suppressor gene. Science (Wash. DC). 260:13171320.

103. Linehan, W.M., M.I. Lerman, and B. Zbar. 1995. Identification of the von Hippel-Lindau (VHL) gene. Its role in renal cancer. J. Am. Med. Assoc. 273:564-570.

104. Chen, F., T. Kishida, M. Yao, T. Hustad, D. Galvac, M. Dean, J.R. Gnarra, M.L. Orcutt, F.M. Duh, G. Glenn, et al. 1995. Germline mutations in the von Hippel-Lindau disease tumor suppressor gene: correlations with phenotype. Hum. Mutat. 5:66-75.

105. Whaley, J.M., J. Naglich, L. Gelbert, Y.E. Hsia, J.M. Lamiell, J.S. Green, D. Collins, H.P.H. Neumann, J. Laidlaw, F.P. Li, et al. 1994. Germ-line mutations in the von Hippel-Lindau tumor suppressor gene are similar to somatic von Hippel-Lindau aberrations in sporadic renal cell carcinoma. Am. J. Hum. Genet. 55:1092-1102.

106. Gnarra, J.R., K. Tory, Y. Weng, L. Schmidt, M.H. Wei, H. Li, F. Latif,
S. Liu, F. Chen, F.M. Duh, et al. 1994. Mutations of the VHL tumor suppressor gene in renal carcinoma. Nat. Genet. 7:85-90.

107. Shuin, T., K. Kondo, S. Torigoc, T. Kishida, Y. Kubota, M. Hosaka, Y. Nagashima, H. Kitamura, F. Latif, B. Zbar, et al. 1994. Frequent somatic mutations and loss of heterozygosity of the von Hippel-Lindau tumor suppresso gene in primary human renal cell carcinomas. Cancer Res. 54:2852-2855.

108. Foster, K., A. Prowse, A. van den Berg, S. Fleming, M.M.F. Hulsbeek, P.A. Crossey, F.M. Richards, P. Cairns, N.A. Affara, M.A. Ferguson-Smith, et al. 1994. Somatic mutations of the von Hippel-Lindau disease tumor suppressor gene in non-familial clear cell renal carcinoma. Hum. Mol. Genet. 3:2169-2173.

109. Kanno, H., K. Kondo, S. Ito, I. Yamamoto, S. Fujii, S. Torigoe, N. Sa-

kai, M. Hosaka, T. Shuin, and M. Yao. 1994. Somatic mutations of the von Hippel-Lindau tumor suppressor gene in sporadic central nervous system hemangioblastomas. Cancer Res. 54:4845-4847.

110. Kibel, A., O. Iliopoulos, J.A. DeCaprio, and W.G. Kaelin. 1995. Binding of the von Hippel-Lindau tumor suppressor protein to Elongin B and C. Science (Wash. DC). 269:1444-1446.

111. Thirman, M.J., D.A. Levitan, H. Kobayashi, M.C. Simon, and J.D. Rowley. 1994. Cloning of $E L L$, a gene that fuses to $M L L$ in a $\mathrm{t}(11 ; 19)$ (q23; p13.1) in acute myeloid leukemia. Proc. Natl. Acad. Sci. USA. 91:12110-12114.

112. Mitani, K., Y. Kanda, S. Ogawa, T. Tanaka, J. Inazawa, Y. Yazaki, and H. Hirai. 1995. Cloning of several species of $M L L / M E N$ chimeric cDNAs in myeloid leukemia with $\mathrm{t}(11 ; 19)(\mathrm{q} 23 ; \mathrm{p} 13.1)$ translocation. Blood. 85:2017-2024.

113. Tkachuk, D.C. S. Kohler, and M.L. Cleary. 1992. Involvement of a homolog of Drosophila Trithorax by 11q23 chromosomal translocations in acute leukemias. Cell. 71:691-700.

114. Gu, Y., T. Nakamura, H. Alder, R. Prasad, O. Canaani, G. Cimino, C.M. Croce, and E. Canaani. 1992. The $\mathrm{t}(4 ; 11)$ chromosome translocation of human acute leukemias fuses the $A L L-1$ gene, related to Drosophila trithorax, to the $A F-4$ gene. Cell. 71:701-708.

115. Rabbitts, T.H. 1994. Chromosomal translocations in human cancer. Nature (Lond.). 372:143-149.

116. Henry, N.L., A.M. Campbell, W.J. Feaver, D. Poon, P.A. Weil, and R.D. Kornberg. 1994. TFIIF-TAF-RNA polymerase II connection. Genes \& Dev. 8:2868-2878

117. Petrij, F., R.H. Giles, H.G. Dauwerse, J.J. Saris, R.C.M. Hennekam, M. Masuno, N. Tommerup, G.J.B. van Ommen, R.H. Goodman, D.J.M. Peters, and M.H. Breuning. 1995. Rubinstein-Taybi syndrome caused by mutations in the transcriptional co-activator CBP. Nature (Lond.). 376:348-351.

118. Schoenmakers, E.F., S. Wanschura, R. Mols, J. Bullerdiek, H. Van Den Berghe, and W.J. van de Ven. 1995. Recurrent rearrangements in the high mobility group protein gene, HMGI-C, in benign mesenchymal tumours. Nat. Genet. 10:436-444.

119. Ashar, H.R., M. Schoenberg Fejzo, A. Tkachenko, X. Zhou, J.A Fletcher, S. Weremowicz, C.C. Morton, and K. Chada. 1995. Disruption of the architectural factor HMGI-C: DNA-binding AT hook motifs fused in lipomas to distinct transcriptional regulatory domains. Cell. 82:57-65. 